\title{
Urothelium-preserving augmentation cystoplasty covered with a peritoneal flap
}

\author{
O. OGE, S. TEKGUL, A. ERGEN and S. KENDI \\ Department of Urology, Hacettepe University School of Medicine, Ankara, Turkey
}

Objectives To present the results of bladder autoaugmentation covered with a peritoneal flap in patients with bladder dysfunction.

Patients and methods Thirteen patients (seven male and six female, mean age 11.9 years, range 4-25) who underwent autoaugmentation covered with a peritoneal flap were evaluated. Seven had different forms of myelodysplasia, four had spinal cord injury and two had Hinman syndrome as the cause of bladder dysfunction. Indications for augmentation included upper tract deterioration, urinary incontinence and recurrent urinary tract infection, despite anticholinergic therapy.

Results The mean bladder capacity increased by $18.6 \%$ after surgery and the mean compliance at capacity increased from 3.4 to $5.8 \mathrm{cmH}_{2} \mathrm{O} / \mathrm{mL}$. All patients were incontinent before surgery and continence was achieved in only six afterward. Four patients showed no clinical or urodynamic improvement and required re-augmentation using intestinal segments. Only three patients needed no anticholinergic therapy after surgery. All four patients in whom the procedure failed had capacities of $<30 \%$ of that expected for their age. There were no metabolic problems.

Conclusion Autoaugmentation combined with a peritoneal flap is an easy procedure but the clinical results are poor in some patients, especially those with a small initial bladder capacity. The need for secondary augmentation with enteric segments was common. The use of a peritoneal flap does not appear to increase the capacity and compliance more than is obtained with the classical technique; it may prevent adhesion to the abdominal wall and make a secondary procedure easier. As the increase in capacity and compliance is limited with this technique, a urothelium-preserving augmentation should be reserved for those bladders with a relatively good initial capacity. Keywords Bladder disease, cystoplasty, augmentation, outcome

\section{Introduction}

Anticholinergic agents and intermittent catheterization are the first-line treatments for high-pressure, smallcapacity bladders. When these treatments fail to increase bladder compliance, surgical bladder augmentation is usually required to achieve an adequate capacity and a safe pressure. Bladder augmentation using intestinal segments and stomach is well established in reconstructive urology. The potential structural and metabolic complications of intestinal augmentation have been well described, and include metabolic acidosis, mucus production, stone formation, the possibility of malignancy and haematuria-dysuria syndrome. Although this form of therapy is useful and successful in preventing renal deterioration and attaining continence, the potential complications have initiated the search for alternative techniques. The use of synthetic materials has not always been satisfactory. Augmentation, i.e. enlarging the

Accepted for publication 18 January 2000 bladder without introducing intestinal epithelium, has become popular over the last few years.

To avoid the complications and long-term risks of gastrocystoplasty and enterocystoplasty, preserving the urothelium and using demucosalized intestinal segments on the preserved urothelium have become popular, and many series with good outcomes have been reported. As an alternative to these urothelium-preserving procedures, Carr and Mitchell [1] described a technique using peritoneum to cover the preserved urothelium and reported encouraging preliminary results. The present report describes the results in patients treated using an autoaugmentation covered with peritoneum.

\section{Patients and methods}

From September 1995 to December 1997, 13 patients (seven male and six female, mean age 11.9 years, range 4-25) underwent bladder autoaugmentation covered with a peritoneal flap. The underlying diagnoses were myelodysplasia in seven, spinal cord injury in four and Hinman syndrome in two patients (Table 1). The 
Table 1 The characteristics and outcome of autoaugmentation in the 13 patients

\begin{tabular}{|c|c|c|c|c|c|c|c|c|}
\hline \multirow{2}{*}{$\begin{array}{l}\text { Patient } \\
\text { sex/age }\end{array}$} & \multirow[b]{2}{*}{ Diagnosis } & \multirow{2}{*}{$\begin{array}{l}\text { Concomitant } \\
\text { procedures }\end{array}$} & \multicolumn{2}{|c|}{ Preoperative* } & \multicolumn{2}{|c|}{ Postoperative* } & \multirow[b]{2}{*}{ Outcome } & \multirow[b]{2}{*}{ Medication } \\
\hline & & & Capacity & Compliance & Capacity & Compliance & & \\
\hline $1 \mathrm{M} / 24$ & SCI & BN wrap, Mit & 60 & 5 & 90 & 12 & Dry, CIC 6-7 h & Oxybutynin \\
\hline $2 \mathrm{~F} / 25$ & SCI & - & 60 & 4 & 100 & 10 & Dry, no CIC & Oxybutynin \\
\hline $3 \mathrm{M} / 10$ & SCI & Mit & 30 & 2 & 60 & 5 & Dry CIC $\times 2 /$ day & None \\
\hline $4 \mathrm{M} / 4$ & Myelo & BN wrap, Mit & 30 & 1 & 30 & 1 & Wet, CIC 5-6h & Oxybutynin \\
\hline $5 \mathrm{~F} / 21$ & Myelo & - & 50 & 4 & 70 & 10 & Wet, no CIC & Oxybutynin \\
\hline $6 \mathrm{M} / 12$ & Myelo & BN wrap, Mit & 18 & 2 & 30 & 2 & Wet, CIC $6 \mathrm{~h} \dagger$ & Oxybutynin \\
\hline $7 \mathrm{~F} / 5$ & Myelo & Uretero (left) & 50 & 4 & 40 & 4 & Wet, CIC $8 \mathrm{~h}$ & Oxybutynin \\
\hline $8 \mathrm{~F} / 8$ & HS & - & 30 & 2 & 90 & 10 & Dry, no CIC & None \\
\hline $9 \mathrm{M} / 6$ & Myelo & BN wrap, Mit & 20 & 1 & 50 & 2 & Wet, CIC 6 h $\dagger$ & Oxybutynin \\
\hline $10 \mathrm{M} / 7$ & Myelo & BN wrap, Mit & 30 & 4 & 50 & 5 & Wet, CIC $\times 2 /$ day & Oxybutynin \\
\hline $11 \mathrm{~F} / 7$ & Myelo & - & 30 & 2 & 30 & 2 & Wet, no $\mathrm{CIC} \dagger$ & Oxybutynin \\
\hline $12 \mathrm{M} / 21$ & SCI & Mit & 70 & 10 & 100 & 12 & Dry, CIC 5-6h & None \\
\hline $13 \mathrm{~F} / 5$ & HS & Uretero (bilateral) & 70 & 3 & 50 & 2 & Dry, CIC 4 h & Oxybutynin \\
\hline
\end{tabular}

* Capacity is expressed as \% of normal for age and compliance in $\mathrm{cmH}_{2} \mathrm{O}$; $\uparrow$ re-augmented.

SCI, spinal cord injury; Myelo, myelodysplasia; BN wrap; bladder neck wrap; Mit, Mitrofanoff; Uretero, ureteroneocystostomy.

indications for augmentation included upper tract deterioration, urinary incontinence and recurrent UTI. All patients except those who had undergone previous bladder surgery or those with very low bladder capacities were offered autoaugmentation or enterocystoplasty during that period. All patients were informed about the possible advantages and disadvantages of the procedure, and informed that autoaugmentation was not as successful as enterocystoplasty.

Maximum anticholinergic therapy and clean intermittent catheterization (CIC) did not improve bladder dysfunction in any of the patients before surgery. The preoperative assessment included video-urodynamics, upper tract imaging and estimation of renal function. Urodynamics showed a mean (range) capacity of 42 (18$70) \%$ of the bladder capacity expected for the age of the patient [2]. The mean compliance at capacity (defined as the volume at a pressure of $40 \mathrm{cmH}_{2} \mathrm{O}$ ) was $3.4(1-$ 10) $\mathrm{cmH}_{2} \mathrm{O} / \mathrm{mL}$. All patients except one had normal renal function and autoaugmentation was performed to prepare the bladder for renal transplantation in that patient.

\section{Surgical technique}

Before surgery all patients underwent bowel preparation for a possible enterocystoplasty. The bladder was catheterized with a Foley catheter attached to a saline bag for irrigation. A Pfannensteil incision was made and the bladder exposed; it was filled to $20 \mathrm{cmH}_{2} \mathrm{O}$ and this pressure was maintained during the procedure to facilitate the dissection. The detrusor muscle was incised from the bladder dome until the bladder mucosa protruded and the detrusor was then dissected off all surfaces of the bladder, leaving the mucosa intact. Small openings in the mucosa were closed with 4-0 chromic sutures. The dissection was stopped at the level of the vesical pedicles. After completing the dissection in an extraperitoneal approach, if the capacity was increased, a peritoneal flap large enough to cover the created bladder diverticulum was freed and the peritoneum closed. In cases with insufficient dissection or no significant improvement in capacity after dissection, the mucosa was excised and enterocystoplasty performed. The peritoneal flap was sutured to the edges of the intact detrusor layer using 3-0 polyglactin interrupted sutures. A Penrose drain was left in the space between the mucosa of the bladder and the peritoneal flap, to drain any fluid. A Foley catheter was left in situ and the abdominal wall closed. The Foley catheter was elevated $15-20 \mathrm{~cm}$ to leave the bladder partly full during healing. The Penrose drain was removed as early as possible, the Foley catheter removed 5-6 days after surgery and CIC resumed. Various procedures (Table 1) were combined with this procedure.

The mean hospitalization period was 7 (5-9) days and all patients returned within 6 months of surgery for a complete evaluation, including video-urodynamics, upper tract imaging, renal function tests and a questionnaire about continence and quality of life.

\section{Results}

No patients died during surgery and no early complications occurred except that the patient with impaired renal function required haemodialysis; renal function 
remained stable in all other patients. No metabolic complications were noted. All patients continued to receive anticholinergic agents after surgery. The mean follow-up was $15(6-27)$ months. The mean bladder capacity increased by $61(30-100) \%$ after surgery and the mean compliance at capacity increased from 3.4 (110) to $5.8(1-12) \mathrm{cmH}_{2} \mathrm{O} / \mathrm{mL}$ (Table 1).

Nine of the patients had uninhibited contractions on urodynamics before surgery and in five the uninhibited contractions resolved completely afterward. Only three patients with a good capacity and compliance and no uninhibited contractions were offered cessation of anticholinergic therapy after video-urodynamics.

All patients were incontinent before surgery and only six attained continence afterward (four on CIC). Of the seven patients who remained incontinent after surgery, two with an adequate bladder capacity but low leak-point pressure underwent bladder neck injection with collagen subsequently; however, they only had a partial improvement and are awaiting a second injection. After a follow-up of $>1$ year, four patients had no clinical or urodynamic improvement and required re-augmentation using intestinal segments, i.e. an ileocystoplasty in two, colocystoplasty in one and the fourth is awaiting enterocystoplasty. After re-augmentation, all three patients fared well and became continent with a good capacity and compliance. A 5-year-old patient had worse urodynamic findings but achieved continence using CIC every $4 \mathrm{~h}$; she has been followed for 15 months with no progression in upper tract deterioration and no improvement in capacity and compliance (Table 1).

Overall, eight patients had better bladder capacity and compliance but two remained incontinent because of decreased bladder outlet resistance; four patients remained stable according to urodynamic findings, and the remaining one showed worsening values. Five of the patients had various grades of VUR before surgery which resolved completely in only two who fared well with autoaugmented bladders; however, VUR persisted in the other three patients in whom the procedure failed, despite concomitant ureteroneocystostomies in two. All the patients in whom the procedure failed had initial capacities of $\leqslant 30 \%$ of the expected value for their age. The best results were achieved both clinically and urodynamically in patients whose initial capacity was more than half of normal.

\section{Discussion}

The most common source of augmentation biomaterial is the gastrointestinal tract and nearly every segment of this tract has been used successfully [3]. However, serious complications have been reported in patients with gastrocystoplasty and enterocystoplasty, including meta- bolic problems [4], mucus production [5], stone formation [6], peptic ulceration [7], malignancy [8] and intractable diarrhoea [7]. Urothelial-lined augmentation became a popular procedure because it preserved native urothelium, caused no mucus production, no metabolic complications and possibly prevented malignant degeneration Cartwright and Snow performed the first urothelium-lined augmentation (autoaugmentation) in children in 1989 [9,10]. They described a technique in which the uncompliant detrusor muscle was excised to create a large pseudodiverticulum at the dome. It was later found that in some patients the urothelial diverticulum ultimately became scarred and adhered to the anterior abdominal wall, becoming as uncompliant as the original neurogenic bladder muscle [11]. As this technique fails to protect the mucosa with the elastic barrier and contractile properties of the normal detrusor, the use of demucosalized intestinal segments on preserved urothelium was combined with bladder autoaugmentation. Various de-epithelialized gastrointestinal segments were used to cover the urothelium.

The technique which Carr etal. [1] described uses peritoneum to cover the preserved urothelium. This technique is much easier, less complicated and does not carry the risks of bowel complications. Both operative duration and hospital stay are much shorter. Using this technique, the present results are similar to those in many reported autoaugmentation studies. Of the 13 patients, 10 had an increased bladder capacity but the mean increase was only $44 \%$; only four patients had a normal capacity $(90-100 \%$ of the expected capacity for age) whereas in the remaining patients it was $<70 \%$ of expected capacity. It was only possible to obtain acceptable capacities in patients whose preoperative capacity was $>60 \%$ of normal.

The increase in compliance was similar to the change in capacity; the mean compliance at capacity increased by only $70 \%$ after augmentation and only four patients had a compliance of $>10 \mathrm{cmH}_{2} \mathrm{O} / \mathrm{mL}$. Although urodynamic improvements were unsatisfactory, the clinical improvement was better; nine patients had a marked clinical improvement, either in upper tract deterioration or in continence. Six patients became completely continent and continence markedly improved in three. Four patients were considered complete failures and underwent re-augmentation using intestinal segments. In those patients explored for re-augmentation, the dome of the bladder was thickened and inelastic; the bladder was easily dissected and there was no heavy scarring or adhesion to the anterior abdominal wall.

As the increase in capacity and compliance was modest with the urothelium-preserving technique, we suggest that it is used in patients whose bladders have a relatively good capacity ( $\geqslant 50 \%$ of normal). The use of a 
peritoneal flap does not give significant advantages in achieving a good capacity and compliance. However, covering the urothelium with a peritoneal flap helps to prevent it adhering to the abdominal wall and thus facilitates a secondary procedure, if needed. The present re-augmentation rate would have been less if the patients had been rigorously selected. Therefore, although the preliminary results were disappointing, there are many patients who could benefit from this technique.

\section{References}

1 Carr MC, Burns MW, Mitchell ME. Bladder augmentation with urothelial preservation. Presented at the American Academy of Pediatrics Annual Meeting 1995

2 Koff SA. Estimating bladder capacity in children. Urology 1983; 21: 248-51

3 Mitchell ME, Piser JA. Intestinocystoplasty and total bladder replacement in children and young adults; follow-up in 129 cases. J Urol 1987; 138: 579-83

4 McDougal WS. Metabolic complications of urinary intestinal diversion. J Urol 1992; 147: 1199-4

5 Murray K, Nurse DE, Mundy AR. Secreto-motor function of intestinal segments used in lower urinary tract reconstruction. Br J Urol 1987; 60: 532-6
6 Blyth B, Ewalt DH, Duckett JW, Snyder HM. Lithogenic properties of enterocystoplasty. J Urol 1992; 148: 575-7

7 Gonzales R, Cabral BPH. Rectal continence after enterocystoplasty. Dial Ped Urol 1987; 10: 4

8 Filmer RB, Spencer JR. Malignancies in bladder augmentations and intestinal conduits. J Urol 1990; 143: 671-8

9 Cartwright PC, Snow BW. Bladder autoaugmentation: partial detrusor excision to augment the bladder without use of bowel. J Urol 1989; 142: 1050-3

10 Cartwright PC, Snow BW. Bladder autoaugmentation: early clinical experience. J Urol 1989; 142: 505-8

11 Donald HN, Mitchell ME, Mark H, Darius JB, Can CG. Demucosalised augmentation gastrocystoplasty with bladder autoaugmentation in pediatric patients. J Urol 1996; 156: 206-9

\section{Authors}

O. Oge, MD, Specialist in Urology.

S. Tekgul, MD, Associate Professor in Urology.

A. Ergen, MD, Professor in Urology.

S. Kendi, MD, Professor in Urology.

Correspondence: Dr Serdar Tekgul, Hacettepe Universitesi Tip Fakultesi, Uroloji Anabilim Dali, 06100 Sihhiye, Ankara, Turkey. 